\title{
Transit Capacity and Quality of Service Manual Applied to a Bus Corridor in Dublin, Ireland
}

\author{
Brian Caulfield and Margaret O'Mahony
}

\begin{abstract}
The introduction of 11 quality bus corridors (QBCs) has been a success story in the provision of public transport in Dublin, Ireland, over the past few years. In a city where the bus is the main mode of public transport, the QBC initiative has resulted in decreased commute times and increased ridership. QBCs operate on dedicated traffic lanes between the hours of 7 a.m. and 7 p.m. and in certain instances on a 24-h basis. The performance of the Malahide QBC, which extends $7.5 \mathrm{~km}(4.7 \mathrm{mi})$ from the city center to the northeast of the city, is measured by examining service coverage, headway, and transit/ automobile travel time (the difference in travel time between transit and private vehicles). The Transit Capacity and Quality of Service Manual (TCQSM) is used to provide quality of service measurements on the corridor to evaluate its performance. Data for the TCQSM analysis were taken from an automatic license plate recognition system that was installed on the Malahide QBC in 2003. Future plans for the QBC network are presented, along with a concluding examination of how QBCs play a role in providing a more efficient public transport system in Dublin.
\end{abstract}

The Greater Dublin Area (GDA) — which consists of Dublin (the capital city) and the counties of Dublin, Kildare, Wicklow, and Meath-is located in eastern Ireland. In 2002 the population of the GDA was 1.5 million; it continues to grow at a significant rate and is expected to reach 1.75 million by 2016 (1). In the past decade, traffic congestion has become a major problem, with the private automobile ownership rate at 342 per 1,000 and predicted to rise to 480 per 1,000 by 2016 (1). Because of the need to reduce congestion, the Irish government has looked into new ways to make public transport a more attractive transport option.

The Dublin Transportation Initiative (DTI) final report was published in 1995 (2). This report was commissioned by the Irish government to find the best way to provide Dublin with an effective transportation strategy. With regard to the public transport infrastructure, the main recommendations of the DTI were to introduce 11 quality bus corridors (QBCs) and to construct a light rail transit system.

The 11 QBCs outlined in the DTI were operational in Dublin in 2001. Because bus services are flexible, they have been relatively quick and cost-effective to implement. QBCs operate on dedicated lanes between 7:00 a.m. and 7:00 p.m. and in some cases on a 24-h

Centre for Transport Research, Department of Civil, Structural, and Environmental Engineering, Trinity College, University of Dublin, Dublin 2, Ireland.

Transportation Research Record: Journal of the Transportation Research Board, No. 1887, TRB, National Research Council, Washington, D.C., 2004, pp. 195-204. basis. They have been implemented radially from the city center, as illustrated in Figure 1.

This paper examines the QBC concept and reports on its success to date in Dublin. Quality of service (QOS) is measured using the Transit Capacity and Quality of Service Manual (TCQSM) (4). The data for some of the measurements have been taken from an automatic license plate recognition (ALPR) system that Dublin City Council (DCC) introduced on the Malahide QBC in 2003. With these data the paper outlines TCQSM requirements relative to headway, hours of service, transit/automobile travel time (the difference in travel time between transit and private vehicles), accessibility, and service coverage.

The first section looks at the concept of bus corridors or lanes, drawing on the experiences in the United States and the United Kingdom. The following section examines TCQSM measures as a means of evaluating the performance of the corridor. The final sections describe the means of data collection, which is then used to detail the TCQSM-based procedure in a case study of the Malahide QBC.

The paper concludes by examining the importance of QBCs and the role they will play in providing a more efficient public transport system in Dublin. Access facilities such as park-and-ride and realtime passenger information (RTPI) systems — which provide passengers at bus stops with up-to-date information on estimated arrival time via Global Positioning System (GPS) data-should also be examined. The role that these facilities could play in improving the attractiveness of QBCs as viable public transport options is also examined.

\section{BUS PRIORITY CORRIDORS OR LANES}

In the United States, the concept of priority corridors for buses as viable alternatives to rail-based solutions is increasingly attractive. Federal incentives have been used to implement bus rapid transit (BRT) corridors because of the costs of implementing rail-based public transport systems $(5,6)$. The following section examines the situation with regard to bus corridors in the United States; London, United Kingdom; and Dublin.

\section{Bus Rapid Transit}

The aim of the BRT projects funded by the U.S. Federal Transit Administration (FTA) is to demonstrate how the bus can be an attractive alternative to rail-based solutions. "BRT is a flexible, rubber-tired rapid transit mode that combines stations, vehicles, 


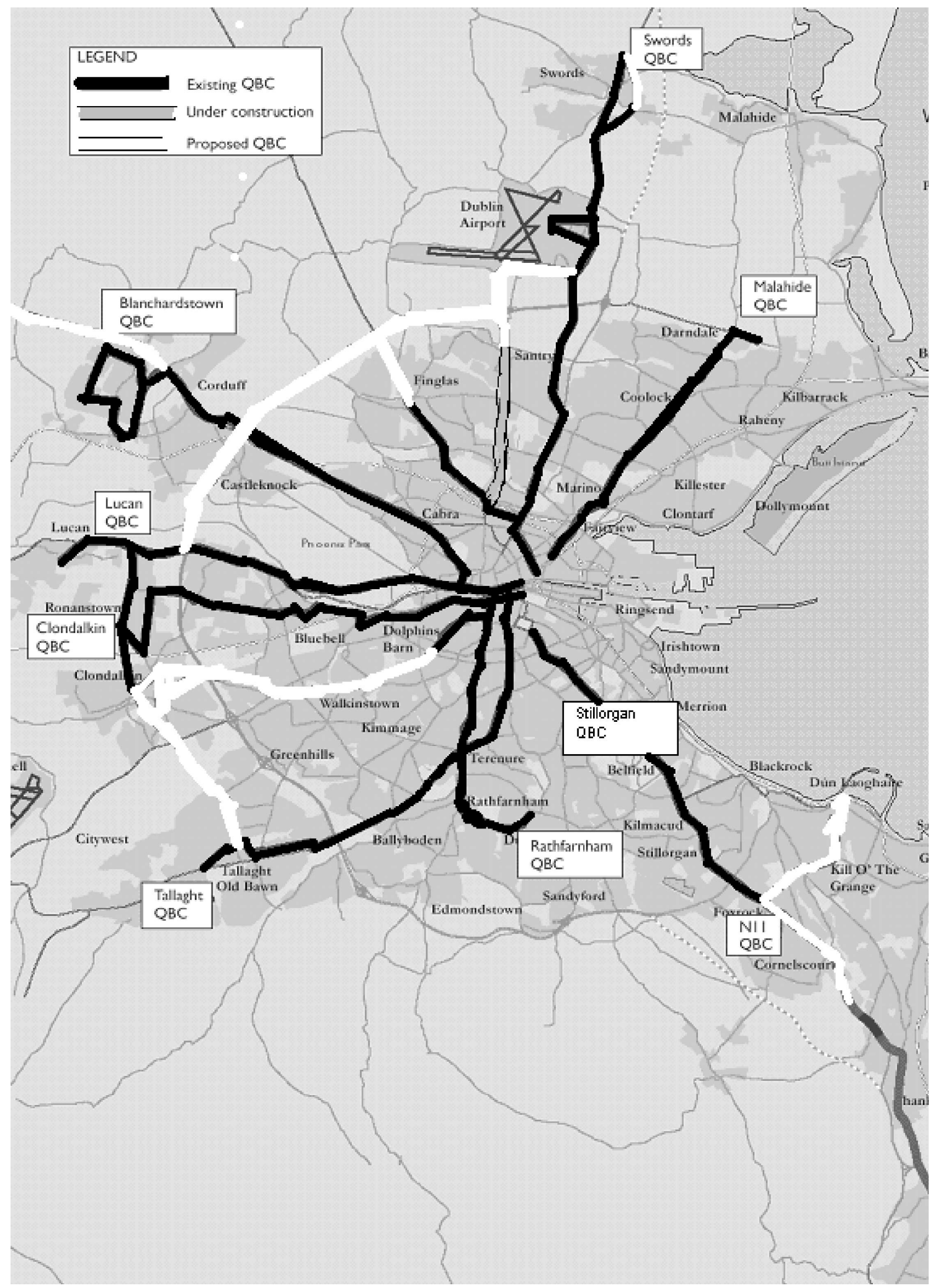

FIGURE 1 QBCs in Dublin, June 2003 (3). 
services, running ways, and intelligent transport systems (ITS) elements into an integrated system with a strong positive image and identity" (5).

The BRT initiative is based on this concept that bus corridors are viable alternatives to rail and private car. BRTs use the following approaches to achieve this goal:

- Signal priority;

- Bus lanes and bus-only roads and tunnels;

- Low-floored electronic and compressed natural gas vehicles;

- Automatic vehicle location (AVL), RTPI, and prepaid ticketing systems; and

- Park-and-ride facilities.

The Wilshire BRT in Los Angeles, California, demonstrates the benefits of implementing a priority corridor for buses. In 2000 overall investment in the Wilshire BRT was \$235 million. The Wilshire BRT is an improvement over the previous Metro Rapid Bus Line 720 extending $22 \mathrm{~km}$ (13.7 mi) from Wilshire (in Los Angeles) to downtown Santa Monica, California. Improvements include highcapacity vehicles, enhanced stations along the route, signal priority, dedicated bus lanes, and smart card prepayment. Since the introduction of the Wilshire BRT, travel times have decreased by $27 \%$ and vehicle capacity increased by $50 \%$. The introduction of a smart card prepayment is anticipated to decrease boarding times and therefore decrease dwell time by $50 \%$ to $65 \%$ (7).

An innovative example of the BRT initiative is the New BritainHartford Busway in Connecticut. In 1999 it was decided after an investment study to construct a busway between New Britain and Hartford. This 15.1-km (9.4-mi) busway now has 12 stations situated along the route (8). A unique feature of this route is that it was constructed on abandoned railroad between the two cities. The system analysis looked at constructing light rail, heavy rail, and bus service along this corridor. On economic and congestion-reducing grounds, the bus was the chosen mode.

The ethos of the BRT is to provide passengers with a service equivalent to that of rail-based services. In Washington, D.C., a stated preference evaluation was conducted that compared Metro services and an express bus-based service with equivalent service standards; results indicated that a high-performance bus service could substitute for rail service (9). Clearly, when evaluating enhanced bus services and rail-based light rail or metro, one should evaluate the modal alternatives on a level playing field, provided that levels of service (LOSs) are comparable.

\section{London Bus Initiative}

London Buses - a division of Transport for London-manages and plans routes, specifies service standards, and monitors these standards for one of the largest bus networks in the world. It operates a fleet of 6,000 buses that provide 4.5 million passenger trips each weekday (10). Since 1994 London Buses has introduced more than 400 sections of bus lane and signal priority at more than 500 traffic junctions. The London Bus Initiative (LBI) is a program aimed at realizing comprehensive improvements in bus services with high levels of bus priority on all major intersections. The LBI makes provisions for the bus lanes to be operated $24 \mathrm{~h} /$ day, with access for buses and emergency vehicles. From the initial stages of LBI introduction, bus journey times have been reduced by $10 \%$ and schedule reliability has improved by $40 \%$ (10).
In line with providing a more efficient bus network, LBI also makes provisions for introducing improved access facilities on bus corridors. These include

- Improved shelters, seating, lighting, maps, and timetables at London's 17,000 bus stops;

- Low-floored buses to improve access, with 3,000 wheelchairaccessible buses;

- RTPI services at 4,000 stops, reaching $60 \%$ of passengers;

- Increased closed-circuit television (CCTV) surveillance on buses to improve safety;

- Lower-emissions buses operating on ultralow-sulfur diesel, and a pilot project assessing fuel cell buses;

- Bus information to be fully integrated between buses, underground, national rail, and the Dockhands light rail; and

- Increased curbside boarding space to ease entry and exit.

These service improvements, coupled with the planned increase in the number of bus lanes, will provide Londoners with an improved bus service whose access facilities are comparable to those of rail service (11).

\section{QBC Program}

From 1996 to 2001, the 11 QBCs outlined in the DTI (2) were implemented in Dublin. They operate in a radial pattern originating in the city center to mainly residential and industrial areas (Figure 1). The services operating on the QBCs are predominately provided by Bus Átha Cliath (BAC), a state-owned company and the principal provider of bus services in Dublin, which operated a fleet of 1,100 buses and provided 146.6 million passenger journeys in 2002 (12). Essential to QBC success is strict traffic management, whereby the Garda Síochána (police force) — in conjunction with the DCC — ensure freeflowing traffic on the QBC. The Garda impose an on-the-spot fine of \$28 for violations of QBC regulations.

The characteristics of the QBCs that have been implemented include

- Dedicated road space between 7:00 a.m. and 7:00 p.m. (some $24 \mathrm{~h}$ ) adjacent to the curb;

- High-frequency service and increased capacity;

- Strict enforcement of QBC regulations;

- Taxi, cyclist, and emergency vehicle access; and

- Capacity of 5,000 passengers per direction per hour.

The capacity of buses compared with private vehicles has been central to the justification of dedicating traffic lanes to public transport. The average car occupancy rate during a peak-hour journey in the GDA is 1.4 people, whereas bus capacity is 54 people-38 times greater (13). It has been calculated that if bus headway were increased to one bus every $2 \mathrm{~min}$, QBC capacity would increase by $250 \%$ (13).

Initial passenger growth figures show an average increase in passenger growth of 50\% and an average time savings of $10 \mathrm{~min}$ across the QBC network (14) (Table 1). Results indicate the Stillorgan QBC, which extends $12.9 \mathrm{~km}(8 \mathrm{mi})$ from the city center to one of the most affluent residential areas to the south of the city and has been evaluated before (15), had the best performance. Patronage on this QBC has increased by $232 \%$ (although it was from a comparatively low base compared with the other routes, as listed in Table 1), and the average time savings is $11 \mathrm{~min}(14)$. 
TABLE 1 QBC Performance Since Launch (14)

\begin{tabular}{|c|c|c|c|c|c|c|c|}
\hline \multirow[b]{2}{*}{ QBC } & \multirow{2}{*}{$\begin{array}{l}\text { Launch } \\
\text { Date }\end{array}$} & \multicolumn{2}{|c|}{ QBC Length } & \multirow{2}{*}{$\begin{array}{l}\text { Time } \\
\text { Savings } \\
\text { (min) }\end{array}$} & \multicolumn{2}{|c|}{ Bus Patronage } & \multirow{2}{*}{$\begin{array}{l}\text { Increase } \\
\text { in } \\
\text { Patronage }\end{array}$} \\
\hline & & Miles & $\mathrm{Km}$ & & Pre-QBC & Post-QBC* & \\
\hline Lucan QBC & July 1996 & 7.5 & 12.1 & 9 & 16328 & 22243 & $36 \%$ \\
\hline Malahide QBC & Dec. 1998 & 4.7 & 7.5 & 8 & 22018 & 28105 & $27 \%$ \\
\hline Stillorgan QBC & Aug. 1999 & 8 & 12.9 & 11 & 9768 & 32425 & $232 \%$ \\
\hline Finglas QBC & July 2000 & 3.7 & 6 & 3 & 8928 & 8974 & $0.5 \%$ \\
\hline Clondalkin QBC & Feb. 2001 & 7.5 & 12.1 & 8 & 14723 & 14405 & $-2 \%$ \\
\hline $\begin{array}{l}\text { Rathfarnham } \\
\text { QBC }\end{array}$ & March 2001 & 4.4 & 7.1 & 30 & 10786 & 14786 & $37 \%$ \\
\hline Swords QBC & April 2001 & 1.8 & 2.9 & 4 & 16829 & 19666 & $17 \%$ \\
\hline Tallaght QBC & April 2001 & 7.5 & 12.2 & 6 & 18916 & 22570 & $19 \%$ \\
\hline $\begin{array}{l}\text { Blanchardstown } \\
\text { QBC }\end{array}$ & Sept. 2001 & 10 & 16.4 & - & 20383 & 28272 & $39 \%$ \\
\hline $\begin{array}{l}\text { Swords } \\
\text { (Airport) } 2001\end{array}$ & Nov. 2001 & 7.2 & 11.7 & - & - & - & \\
\hline Average & & & & $10 \mathrm{~min}$ & & & $50 \%$ \\
\hline
\end{tabular}

* Based on BAC patronage for November 2002

BAC carried out extensive market research on the Stillorgan QBC in 1999. Results indicated that of the passengers surveyed, $70 \%$ had an alternative mode of transport available, and $72 \%$ of passengers were satisfied with the QBC. With regard to travel time, 73\% of passengers indicated that the QBC was quicker than their previous mode of transport, and $60 \%$ of the new customers had previously traveled by car (16).

\section{MEASURING QUALITY OF SERVICE ALONG TRANSPORT CORRIDORS}

TCQSM defines measures for QOS along transport corridors, which are defined in terms of both QOS and LOS that the mode provides. The manual also details the physical infrastructure along the route with regard to access to stops, the facilities that are provided at the stops, and how improved access facilities can improve overall QOS.

In 2001 the Florida Department of Transportation (Tallahassee) required that all transit services with fixed-route public transport services undertake a performance assessment using the TCQSM procedure. This was the first statewide application of TCQSM-based assessments in the United States. The data collection for the measurements relied on the use of ITS applications such as AVL and automatic passenger counting (APC) (17) to minimize costs. The results for Florida provided the state department of transportation with information about the performance of public transit in the state. State officials have used this evaluation as a means to justify increased statewide investment in public transit.

In Dublin, the operator (in this case, BAC) defines a QOS. BAC has a passenger charter that defines an LOS that BAC has committed to provide to its passengers. The charter defines levels of reliability stating that $92 \%$ of services will operate within 5 min of schedule; all buses will be cleaned every day, with a complete valet service at least once every 4 weeks; all BAC properties will be cleaned daily; passenger information will be accurate; and regular vehicle inspections will ensure that lighting and heating standards are maintained (17).

In conjunction with the $\mathrm{QBC}$ introduction, $\mathrm{BAC}$ conducted extensive market research from October 2000 to March 2001 as a mixture of door-to-door interviews, on-bus interviews, and spot checks on LOS and observed departure times. During the observed period, approximately half a million observations were recorded. Overall results of the survey indicated that $65 \%$ to $70 \%$ of passengers were satisfied with the service BAC provided (16).

\section{AUTOMATIC LICENSE PLATE RECOGNITION}

ALPR is a technology used for the purposes of automatically identifying a vehicle. ALPR systems operate with the use of infrared cameras and high-resolution digital cameras situated in the same manner as CCTV cameras along the corridor. The cameras record vehicle license plates as they pass, and data are sent to a control unit where the information is analyzed.

One of the most recent applications of an ALPR system has been in London to enforce the recent congestion charges. The scheme uses ALPR cameras placed at 230 locations to monitor all access points to the congestion cordon at a cost of $\$ 325$ million. To date this system has managed to account for $90 \%$ of all traffic passing through the cordon each day (18).

The Finnish Roads Administration implemented a system of traffic information in a variable message sign (VMS) system along a stretch of highway extending $28 \mathrm{~km}$ (17 mi) from Lahti, just outside Helsinki, to Heinola, a popular weekend resort. Because of the resort's popularity, weekend traffic is heavily congested along this route. ALPR cameras have been installed at four locations along the highway; data from these cameras are relayed to a control center, which in turn relays the estimated time of arrival in Heinola to the VMS displays located along the corridor (19).

A similar system was installed on a Florida highway between Orlando and Orange County. This system uses information from E-PASS toll transponders that collect data on vehicle movements on the highway - a technology equivalent to ALPR. The data are used to calculate real-time travel times across the $90-\mathrm{km}(55-\mathrm{mi})$ stretch of highway. The system has been in operation since 2001 and provides the transportation authority with real-time traffic speeds along the highway (20).

In January 2003, the Office of the Director of Traffic in the DCC installed an ALPR system at eight locations on the Malahide QBC, four inbound and four outbound (Figure 2). The system provides DCC with real-time vehicle travel time over three stretches of the Malahide QBC: Sections 1, 2, and 3 (as noted in Figure 2). The system uses infrared imaging to recognize vehicle license plates. 


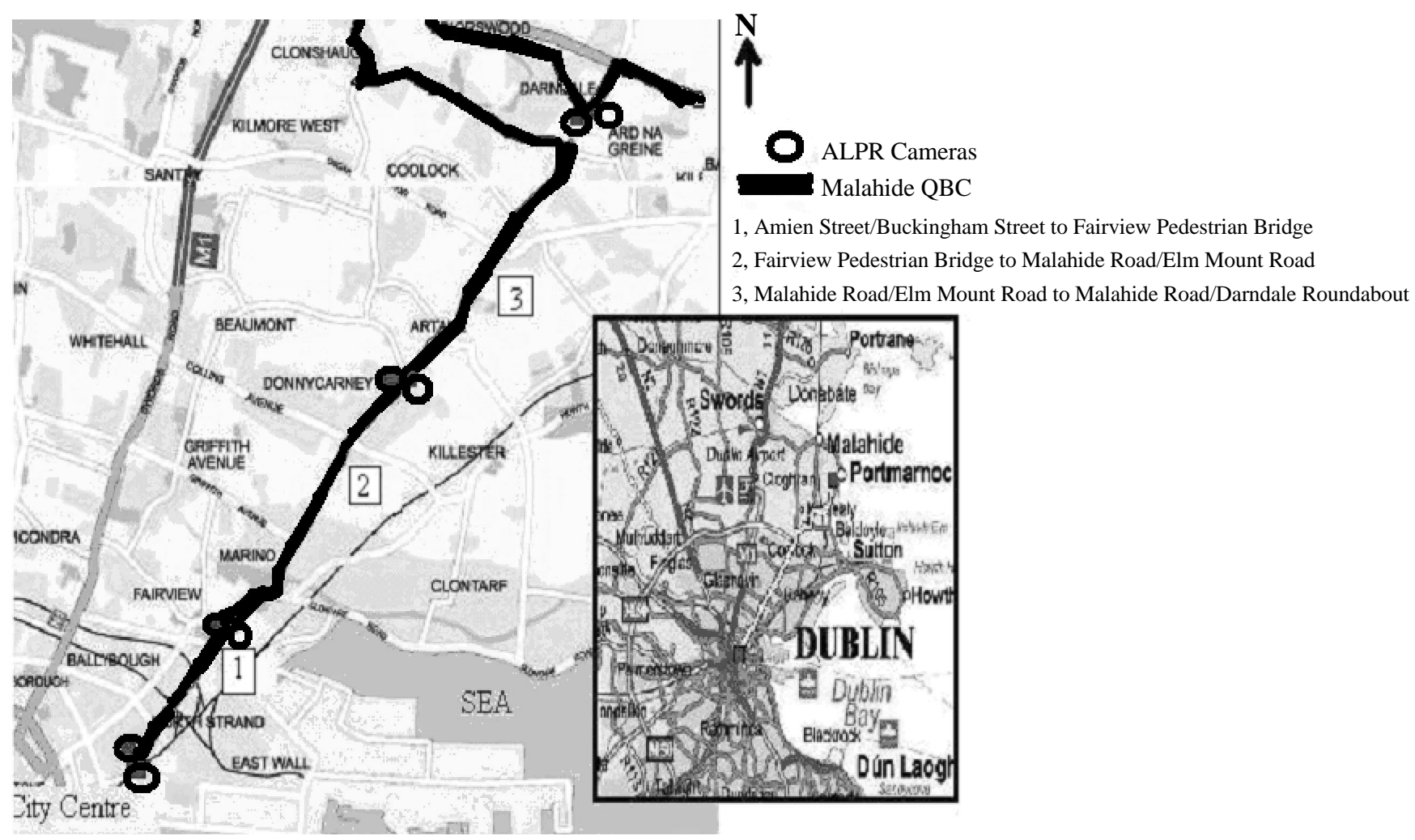

FIGURE 2 Map of Malahide QBC.

This ALPR system can differentiate BAC vehicles from all other vehicles because it is cross-referenced with the BAC license plate database. Therefore, the system can identify buses that travel along the QBC. This differentiation enables DCC to analyze how the two modes of transport compare relative to travel times and average speed. Some of the measures from TCQSM used in the Malahide QBC case study are based on measurements that use ALPR.

\section{CASE STUDY OF MALAHIDE QBC}

The Malahide QBC was completed in December 1998 and extends $7.5 \mathrm{~km}(4.7 \mathrm{mi})$ to the northeast of Dublin (Figure 1). Since its inception, the corridor has realized an average time savings of $8 \mathrm{~min}$ for passengers and a $27 \%$ increase in patronage from 22,018 to 28,105 (14). The LOS measures outlined in the TCQSM that were examined in this study were service frequency, hours of service, and transit/automobile travel time.

\section{Hours of Service}

Hours of service are defined as the hours during the day when transit service is provided along the route. Table 2 lists this LOS on the Malahide QBC, taken from bus operating schedules (21). The results show an LOS of A during weekdays, inbound and outbound, and on Saturdays inbound. There is a lower LOS of C on Sundays and B on Saturdays outbound. The BAC service provided on the QBC extends from 5:15 a.m. on weekdays to the latest services, Nitelink, which operate Monday through Wednesday until 2:00 a.m. and Thursday through Saturday until 4:30 a.m.

\section{Transit/Automobile Travel Time}

The data for transit/auto travel time are based on the average time taken to travel between two points on each of Sections 1 and 2; Section 3 was not used in this analysis because some buses take

TABLE 2 Hours of Service LOS

\begin{tabular}{||l|l|l|l||}
\hline Direction & Hours of Service (21) & LOS & TCQSM Comments (4) \\
\hline Inbound & A & Night owl service provided \\
\hline Weekdays & 20 & A & Night owl service provided \\
\hline Saturday & 23 & C & Early evening service provided \\
\hline Sunday & 16 & A & Night owl service provided \\
\hline Outbound & 20 & B & Late evening service provided \\
\hline Weekdays & 20 & C & Early evening service provided \\
\hline Saturday & 18 &
\end{tabular}


TABLE 3 Transit/Automobile Travel Time LOS

\begin{tabular}{|c|c|c|c|c|c|c|c|c|}
\hline \multirow[b]{3}{*}{ Time } & \multicolumn{4}{|l|}{ Weekdays } & \multicolumn{4}{|l|}{ Weekends } \\
\hline & \multicolumn{2}{|l|}{ Inbound } & \multicolumn{2}{|l|}{ Outbound } & \multicolumn{2}{|l|}{ Inbound } & \multicolumn{2}{|l|}{ Outbound } \\
\hline & $\begin{array}{l}\text { Time } \\
\text { (min:sec) }\end{array}$ & LOS & $\begin{array}{l}\text { Time } \\
\text { (min:sec) }\end{array}$ & LOS & $\begin{array}{l}\text { Time } \\
\text { (min:sec) }\end{array}$ & LOS & $\begin{array}{l}\text { Time } \\
\text { (min:sec) }\end{array}$ & LOS \\
\hline 07:00-08:00 & $02: 10$ & $\mathrm{~B}$ & $04: 20$ & $\mathrm{~B}$ & ${ }^{*}$ & ${ }^{*}$ & ${ }^{*}$ & ${ }^{*}$ \\
\hline 08:00-09:00 & $06: 45$ & $B$ & $04: 18$ & $\mathrm{~B}$ & * & * & ${ }^{*}$ & * \\
\hline 09:00-10:00 & $02: 10$ & $\mathrm{~B}$ & $05: 19$ & $\mathrm{~B}$ & * & * & * & * \\
\hline 10:00-11:00 & $01: 23$ & $A$ & 03:01 & $B$ & $00: 40$ & $\mathrm{~B}$ & 01:05 & $\mathrm{B}$ \\
\hline 11:00-12:00 & 01:06 & $B$ & $04: 13$ & $\mathrm{~B}$ & $02: 16$ & $\mathrm{~B}$ & $00: 30$ & $\mathrm{~B}$ \\
\hline 12:00-13:00 & $00: 33$ & B & 02:05 & B & 01:17 & B & 03:04 & B \\
\hline 13:00-14:00 & $00: 50$ & B & 03:49 & B & 01:32 & B & 04:27 & B \\
\hline 14:00-15:00 & $00: 45$ & B & 04:52 & B & $00: 49$ & B & $04: 14$ & B \\
\hline $15: 00-16: 00$ & $00: 18$ & B & $02: 46$ & B & $00: 54$ & A & 01:52 & B \\
\hline $16: 00-17: 00$ & 01:01 & $\mathrm{B}$ & $00: 50$ & A & 01:12 & B & $00: 44$ & B \\
\hline $17: 00-18: 00$ & 01:05 & $\mathrm{B}$ & $02: 20$ & $\mathrm{~B}$ & $00: 23$ & B & 03:02 & B \\
\hline 18:00-19:00 & 01:04 & B & 01:04 & A & $00: 42$ & B & $00: 27$ & B \\
\hline 19:00-20:00 & 01:18 & $\mathrm{B}$ & $00: 58$ & $\mathrm{~B}$ & $01: 10$ & $\mathrm{~B}$ & 01:06 & $\mathrm{B}$ \\
\hline $\begin{array}{l}\text { Average } \\
\text { Difference }\end{array}$ & $01: 37$ & $B$ & 03:39 & $B$ & $04: 19$ & B & 02:03 & $B$ \\
\hline
\end{tabular}

* Data not available

a detour and enter a residential area in Section 3 and others do not. The data used are the hourly averages observed in April and May 2003 between 7:00 a.m. and 7:00 p.m.

This LOS indicator measures the difference in travel time between two points on the route by bus and by car. As listed in Table 3 , the average differences between the two modes were $1 \mathrm{~min} 37 \mathrm{~s}$ inbound and $3 \mathrm{~min} 39 \mathrm{~s}$ outbound, where the car was faster in both directions. LOS B was therefore observed, which is defined as "about as fast by transit as by automobile" (3). LOS A, defined as "faster by transit than by auto," was observed for 10:00 to 11:00 a.m. inbound, 4:00 to 5:00 p.m. outbound, and 6:00 to 7:00 p.m. outbound services for Sections 1 and 2 of the QBC.

The ALPR system measures the travel times of the buses that travel between two points on the corridor, as explained earlier. The services that join the corridor feed passengers from the surrounding areas and circulating passengers onto the QBC.

From the analysis over the $12-\mathrm{h}$ observed period, the average speeds of buses and cars were calculated (Figure 3). Results indi- cate that the bus maintains a steady average speed throughout the day, whereas the average speed of other traffic is less constant. During the day, the car is quicker; during the morning peak, the average speed is the same for bus and car, at $14 \mathrm{~km}(8.6 \mathrm{mi})$ per hour in both directions.

The transit/auto travel time LOS in Table 3 accounts for only invehicle time. Time penalties such as walk time to and from both modes, wait time for public transport, transfer time from transit or automobile to destination, and time required to park a car were not applied. The TCQSM assumes a transfer time of $11 \mathrm{~min}$ for transit users and $3 \mathrm{~min}$ for automobile users (3). For a transit user, there is an assumed walk of $0.4 \mathrm{~km}(0.25 \mathrm{mi})$ to and from the appropriate mode of transport and a 5-min wait time for transit. The time penalty for automobile users is $3 \mathrm{~min}$, which is the assumed time to park a car and walk to the destination. This equates to a 9-min modal penalty on transit users. If this modal penalty were applied to the results in Table 3, it would affect the LOS by resulting in an LOS B for all the transit/auto travel time

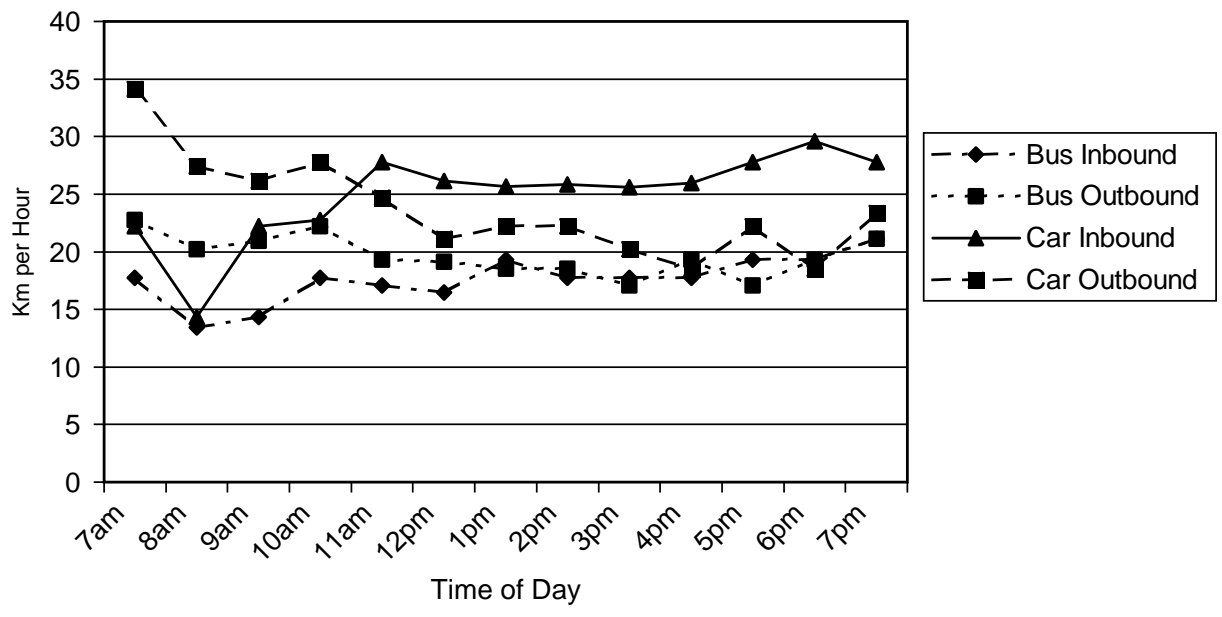

FIGURE 3 Transit/auto speed comparisons $(1 \mathrm{~km}=0.622 \mathrm{mi})$. 
LOS, with the exception of an LOS C inbound between 8:00 and 9:00 a.m.

\section{Accessibility}

BAC introduced low-floor fully accessible buses in 2000. These low-floored buses are fitted with kneeling suspension (to reduce entry step height) and a retractable ramp that allows bus access. On board, wheelchair passengers have dedicated space with grip bars and palm activated bells to stop the bus.

These new vehicles also have lower engine exhaust emissions. In 2002 BAC operated 359 of these buses, amounting to $34 \%$ of the fleet (12). Seven routes on the Malahide QBC use these fully accessible buses. The buses have an average scheduled frequency on the QBC of 5.5 vehicles per hour, both inbound and outbound, from 7:00 to 11:00 a.m. (21).

\section{Service Frequency}

Service frequency is defined as headway observed on the route. The TCQSM defines it by the number of vehicles per hour or the headway in minutes. The APLR system was used to measure the average weekday LOS on the corridor. The data used for the analysis are hourly averages from the first 3 weeks of June 2003. The results listed in Table 4 show an average LOS of A, defined as "passengers do not need schedules" (3).

This LOS was measured for all three sections of the QBC, inbound and outbound. The results should be examined for each section because the number of buses on each segment of the corridor increases as the corridor approaches the city center and more services join the QBC. A high degree of variability exists on each section during the day, and in some cases there is no noticeable increase in the LOS for peak periods. Although there generally are more buses per hour on Section 1, the standard deviation over the day is 8.4 compared with 4.2 and 4.78 for Sections 2 and 3.

\section{System Coverage}

System coverage measures the area within walking distance of a transit service. It was calculated using geographic information system (GIS) technology (Dublin Transportation Office system). The TCQSM defines the coverage area as the air distance within $400 \mathrm{~m}$ ( $0.25 \mathrm{mi})$ of the area served by a fixed-route bus stop (3); therefore, any area within this distance is covered by the service.

Along the Malahide QBC this LOS was measured on Section 1, inbound and outbound. Figure 4 illustrates the results in the transport capture area for an inbound transit stop. The GIS analysis of the area indicated that 295 residential units on the inbound route

TABLE 4 Service Frequency LOS

\begin{tabular}{|c|c|c|c|c|c|c|}
\hline \multirow{2}{*}{$\begin{array}{l}\text { Sections } \\
\text { Time }\end{array}$} & \multicolumn{2}{|l|}{1} & \multicolumn{2}{|l|}{2} & \multicolumn{2}{|l|}{3} \\
\hline & Buses/Hour & LOS & Buses/Hour & LOS & Buses/Hour & LOS \\
\hline \multicolumn{7}{|l|}{ Inbound } \\
\hline 07:00-08:00 & 4 & $\mathrm{C}$ & 1 & $E$ & 1 & $E$ \\
\hline 08:00-09:00 & 18 & A & 10 & $\mathrm{~A}$ & 10 & $\mathrm{~A}$ \\
\hline $09: 00-10: 00$ & 41 & $A$ & 15 & $A$ & 15 & $A$ \\
\hline 10:00-11:00 & 23 & A & 14 & A & 10 & A \\
\hline $11: 00-12: 00$ & 20 & A & 15 & A & 14 & $A$ \\
\hline $12: 00-13: 00$ & 24 & $A$ & 11 & $A$ & 6 & $A$ \\
\hline $13: 00-14: 00$ & 26 & $A$ & 11 & $A$ & 6 & $A$ \\
\hline 14:00-15:00 & 18 & A & 11 & A & 7 & A \\
\hline $15: 00-16: 00$ & 18 & A & 12 & $A$ & 7 & A \\
\hline $16: 00-17: 00$ & 23 & A & 7 & A & 3 & C \\
\hline 17:00-18:00 & 28 & A & 19 & A & 11 & A \\
\hline 18:00-19:00 & 23 & $\mathrm{~A}$ & 12 & A & 10 & $\mathrm{~A}$ \\
\hline 19:00-20:00 & 18 & $A$ & 11 & A & 18 & $A$ \\
\hline Average & 21 & A & 8 & A & 11 & A \\
\hline \multicolumn{7}{|l|}{ Outbound } \\
\hline $07: 00-08: 00$ & 1 & $\mathrm{~F}$ & 2 & $\mathrm{D}$ & 0 & $\mathrm{~F}$ \\
\hline $08: 00-09: 00$ & 16 & A & 8 & $\mathrm{~A}$ & 4 & C \\
\hline $09: 00-10: 00$ & 20 & $A$ & 16 & $A$ & 8 & $\mathrm{~A}$ \\
\hline 10:00-11:00 & 29 & $A$ & 11 & $A$ & 2 & $\mathrm{D}$ \\
\hline $11: 00-12: 00$ & 11 & A & 11 & A & 8 & $A$ \\
\hline $12: 00-13: 00$ & 12 & A & 11 & A & 5 & $B$ \\
\hline $13: 00-14: 00$ & 8 & A & 7 & A & 9 & $A$ \\
\hline $14: 00-15: 00$ & 18 & $A$ & 11 & $A$ & 8 & $A$ \\
\hline $15: 00-16: 00$ & 9 & $A$ & 9 & $A$ & 5 & $B$ \\
\hline $16: 00-17: 00$ & 12 & $A$ & 10 & $A$ & 6 & $\mathrm{~A}$ \\
\hline $17: 00-18: 00$ & 18 & $A$ & 17 & $A$ & 11 & $A$ \\
\hline $18: 00-19: 00$ & 30 & $A$ & 16 & $A$ & 11 & $A$ \\
\hline 19:00-20:00 & 33 & $A$ & 15 & A & 9 & $A$ \\
\hline Average & 16 & A & 11 & A & 6 & A \\
\hline
\end{tabular}

Sections of Malahide QBC: 1, Amien Street/Buckingham Street to Fairview Pedestrian Bridge;

2, Fairview Pedestrian Bridge to Malahide Road/Elm Mount Road; 3, Malahide Road/Elm Mount Road to Malahide Road/Darndale Roundabout. 


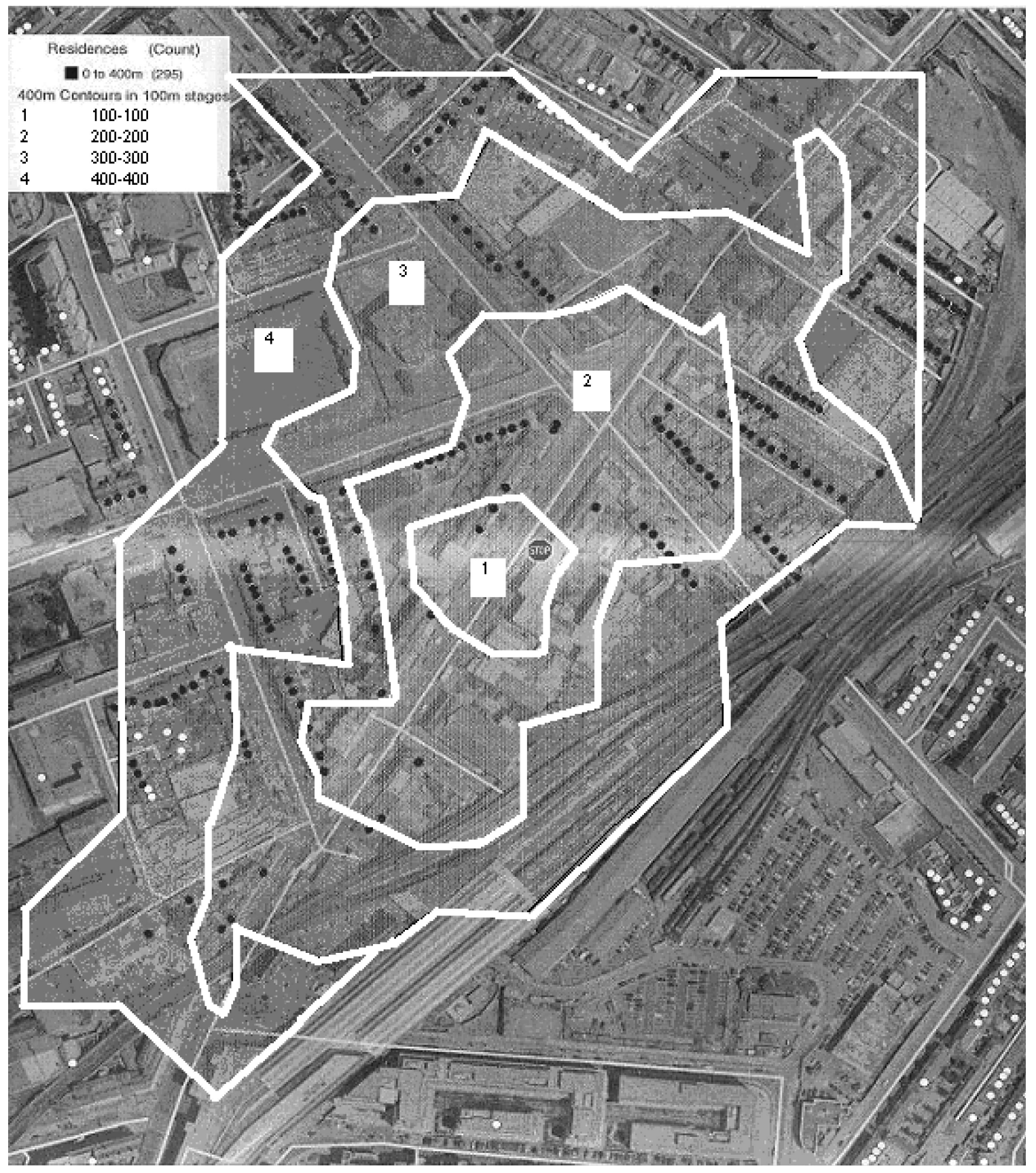

FIGURE 4 GIS map of Section 1 inbound.

and 225 residential units on the outbound route were within a 400-m (437.4-yd) walk of the stop. Homes of residents are displayed as circles: black circles are within walking distance, and white circles are not. The GIS land use model (Dublin Transportation Office) assumes that 2.7 people inhabit each residential zone, so 608 people outbound and 797 inbound are within a 400-m (0.25-mi) walk of the stop.

Overall, the LOS provided on the Malahide QBC has been quite high. All of the LOS measures were between A and C, demonstrating a high QOS on the QBC. In the results that use the ALPR system, one must take into account that this data system captures $80 \%$ of all vehicles. Not always does a bus recognized by the system have passengers, because it may be returning to the depot; therefore, the number of buses in service may be overestimated.

\section{FUTURE OF QUALITY BUS CORRIDORS IN DUBLIN}

As mentioned earlier, passenger numbers grew by $27 \%$ between 1998 and 2001. Recent figures comparing passenger numbers in November $2001(31,625)$ and 2002 revealed a $0.06 \%$ increase (14). This section details some improvements to the service and access facilities that if provided could result in increased patronage. 
The Malahide QBC case study and the results in Table 1 detail the success and benefits of Dublin's QBC program. However, the QBC network still has some shortcomings. To realize the full potential of QBCs, the future direction of the program should take a direction similar to that of BRT in the United States and LBI in London by improving access to facilities and making bus travel as comfortable and convenient as rail-based travel. To this end, there are plans to increase the number and use of QBCs, park-and-ride facilities, prepaid smart card ticketing, and RTPI.

\section{Increased Network}

With regard to QBCs, the aim is to increase the capacity of the bus network, provide orbital and local routes, expand the fleet, add bus priority measures, and increase the number of QBC routes. These improvements to the network are estimated to cost $\$ 930$ million (1). Such improvements include the ITS applications and park-and-ride facilities detailed below.

\section{Smart Card Prepaid Ticketing}

Integrated ticketing using contactless smart card technology is planned in the medium term for the GDA. This system will integrate fare structures, modes, and operators with the use of a single ticket. One of the main advantages of this system will be to reduce the dwell time at stops by increasing the boarding efficiency. As in the Los Angeles BRT, dwell times are expected to be reduced by $50 \%$ to $65 \%$ with the introduction of a similar system (6).

\section{Real-Time Passenger Information}

RTPI exists on three QBCs in Dublin to provide expected time of arrival and different route variants at stops on the Lucan, Clondalkin, and Blanchardstown QBCs, all located to the southwest of the city (Figure 1).

Q-time, a BAC pilot program to test the introduction of RTPI on these corridors, is in its first stage. The 3-year project started in 2000 and is nearing completion. It is planned to achieve systemwide RTPI, covering all modes, by 2010 . The extension of this system has been justified in A Platform for Change as a means to integrate the transportation network between modes and operators (1). No research has been published on the success of the pilot Q-time project to date.

\section{Park and Ride}

The DTO has examined placing park-and-ride facilities in proximity to the city center near QBCs (22). The initial analysis looked at 22 potential sites and analyzed their performance with regard to estimated passengers and revenue per year. The sites were chosen because of their proximity to QBCs and national primary roads. From the potential sites, three QBC sites were rated as having the most potential as park-and-ride locations: Lucan QBC (Fronthill Road), Blanchardstown QBC (Castleknock), and Stillorgan QBC (Cornelscourt) (22).

Ridership levels were estimated by applying an incremental intercept rate to the traffic flow level past the location of the site. The value used for this rate was $0.86 \%$, which was found to represent the reduction in cars for every $1 \mathrm{~min}$ of time savings in relative bus and car journeys after completion of the QBC schemes in Dublin $(0.86 \%$ transfer to bus per 1 -min change in relative bus and car journey times).

\section{CONCLUSIONS}

The TCQSM-based performance assessment carried out on the Malahide QBC indicated that

- The corridor provides an efficient service. All of the LOS measures had results between $\mathrm{A}$ and $\mathrm{C}$, but most were A or B.

- The transit/auto travel time comparison demonstrates that in the majority of instances, the bus service provided is as fast as the car. However, this LOS measure does not take into account the different modal penalties inherent to public and private transport.

- The hours of service on the corridor are extensive. The BAC Nitelink service extends the operating hours of the corridor, and passengers may use the service up to $20 \mathrm{~h}$ /day.

- Using the same strategy for TCQSM-based performance assessment as in Florida would provide a useful comparison of QOS of modes and operators in Dublin. If done on a regular basis with a strict set of guidelines, the evaluation could provide transport planners with comparable results that could demonstrate how system improvements have affected the QOS.

- The use of ITS applications such as ALPR would lower the cost of monitoring and provide a much more comprehensive set of results.

- If ALPR systems were installed on the other 11 QBCs, transport planners would be provided with a comprehensive database of QBC performance.

\section{FUTURE WORK}

It would be interesting to extend this analysis to compare bus- and rail-based corridors in Dublin using the same criteria (i.e., TCQSM), particularly when the new light rail corridors commence in 2004.

Providing high-quality public transport corridors from outside the GDA has also been considered (e.g., to Navan, northwest of the city). An interesting analysis would be to review it in a similar way to the BRT initiative in Connecticut, where an analysis looked at constructing light rail, heavy rail, and a bus service along the corridor in terms of the LOS that might be achieved.

\section{ACKNOWLEDGMENTS}

The research is supported by the Department of Transport under the Pilot Transport Research Programme, administered by the Higher Education Authority. The authors acknowledge the help of Dublin City Council and the Dublin Transportation Office.

\section{REFERENCES}

1. A Platform for Change. Dublin Transportation Office, Dublin, Ireland, Sept. 2000.

2. Gleave, S. D. Dublin Transportation Initiative Final Report. Department of the Environment, Dublin, Ireland, 1995.

3. Dublin Transportation Office Website. www.dto.ie/qbc.pdf. Accessed July 21, 2003.

4. TCRP and Kittelson \& Associates, Inc. TCRP Web Document 6: Transit Capacity and Quality of Service Manual. Project A-15, Contractor 
Final Report. TRB, National Research Council, Washington, D.C., Jan. 1999. gulliver.trb.org/publications/tcrp/tcrp_webdoc_6-a.pdf.

5. Levinson, H., S. Zimmerman, J. Clinger, and J. Gast. Bus Rapid Transit: Synthesis of Case Studies. In Transportation Research Record: Journal of the Transportation Research Board, No. 1841, TRB, National Research Council, Washington, D.C., 2003, pp. 1-11.

6. Baltes, M. R. Statistical Estimation of Importance Customers Place on Specific Service Characteristics of Bus Rapid Transit. Paper presented at the 82nd Annual Meeting of the Transportation Research Board, Washington, D.C., 2003.

7. Papandreou, T. N. Wilshire Bus Rapid Transit: More Than Just a Dedicated Bus Lane. Paper presented at the 82nd Annual Meeting of the Transportation Research Board, National Research Council, Washington, D.C., 2003.

8. Watkins, K. E., T. Sorenson, and N. Garrick. Platform Layout for the New Britain to Hartford Busway. In Transportation Research Record: Journal of the Transportation Research Board, No. 1791, TRB, National Research Council, Washington, D.C., 2002, pp. 21-25.

9. Akiva, B., and M. Takayuki. Comparing Ridership Attraction of Rail and Bus. Transport Policy, Vol. 9, 2002, pp. 107-116.

10. The Mayor's Transport Strategy. Transport for London, London, July 2001.

11. Bus Priority and Traffic Unit Annual Review. Transport for London, London, 1998.

12. CIE Group Annual Report and Financial Statements 2002. Córas Iompair Éireann, Dublin, Ireland, 2002.

13. Traffic Management Guidelines. Dublin Transportation Office, Dublin, Ireland, May 2003.
14. $Q B C$ Report to $\mathrm{OBC}$ Committee/Steering Committee. Dublin Transportation Office, Dublin, Ireland, Sept. 2002.

15. O'Mahony, M. Quality Bus Corridors in Dublin. In Transportation Research Record: Journal of the Transportation Research Board, No. 1791, TRB, National Research Council, Washington, D.C., 2002, pp. $121-126$.

16. Bus Átha Cliath. Market Research Studies by Dublin Bus. www. dublinbus.ie/home/market_research.asp. Accessed June 30, 2003.

17. Bus Átha Cliath. Customer Charter. www.dublinbus.ie/home/customer charter.asp. Accessed July 14, 2003.

18. Road Traffic Technology. Central London Congestion Charging, United Kingdom. www.roadtraffic-technology.com/projects/congestion/. Accessed June 4, 2003.

19. Al-Deek, H., and J. Klodzinski. Simulation and Evaluation of the Orlando-Orange County Expressway Authority (OOCEA) Electronic Toll Collection Plazas Using TPSIM, Phase II. Report prepared for the Florida Department of Transportation Research Center. University of Central Florida, Orlando, July 2001.

20. Ciccarelli, A., L. Griffin, and M. D'Angelo. The Orlando-Orange County Express Authority's Traffic Data Collection Pilot Project. In Proc., 9th World Congress on ITS (CD-ROM). Chicago, Ill., 2002.

21. Bus Átha Cliath. Dublin North Map. www.dublinbus.ie/your_journey/ search_by_map.asp?map=dublin_north. Accessed June 30, 2003.

22. TAS Partnership. Bus-Based Park and Ride: A Pilot Scheme. Dublin Transportation Office, Dublin, Ireland, Oct. 2002.

Publication of this paper sponsored by Transit Capacity and Quality of Service Committee. 